\title{
A GIS-index integration approach to groundwater suitability zoning for irrigation purposes
}

\begin{abstract}
In recent decades, the high population growth has increased the demand for agricultural lands and products. Groundwater offers reliability and flexibility in access to water for irrigation purposes, especially in arid and semi-arid areas, such as Amol-Babol Plain, Iran. However, the quality and quantity of groundwater may not be suitable for irrigation purposes in all areas due to urbanizations, and intensive agricultural and industrial activities. Groundwater suitability zoning for irrigation purposes could be useful to improve water resources and land use planning, mostly in areas with water scarcity. Therefore, a GIS-based indices method is proposed to assess suitable zones for agricultural activities, integrating the irrigation water quality (IWQ) index and hydrogeological factors. IWQ index was utilized to assess groundwater quality based on salinity hazard, infiltration hazard, specific ions, and trace elements hazards, and miscellaneous effects such as $\mathrm{pH}$, bicarbonate, and nitrate. The potential of the aquifer for irrigation water abstraction was investigated using hydrogeological surveys such as slope angle of the plain, hydraulic conductivity, and aquifer thickness. The groundwater suitability index classified most of the study area (more than 90 $\%$ ) as "excellent" or "good" suitability zones for irrigation purposes. A limited area of around $5.6 \%$ of the total area has moderate suitability for irrigation purposes due to the Caspian Seawater intrusion and the presence of fossil saline water. The proposed methodology provides useful information in order to allow irrigation management to prevent water and soil deterioration.
\end{abstract}

Keyword: Index method; GIS; Irrigation water quality; Suitability zone; Amol-Babol plain 